\title{
Digitisation and the Disappearing Job Theory: A Role for the ILO in Africa?
}

\author{
Stefano Bellucci and Eric E. Otenyo
}

\begin{abstract}
For a coherent framework for understanding the future of work, there is a need to unify theories on the role of digitisation in any potential job losses. Is it possible that digitisation not only achieves efficiencies but also retains or creates jobs in selected sectors of African economies? With Africa's population expected to reach 2 billion by 2050, can we be content with the fact that the impact of digitisation has been mostly discussed in the context of advanced economies? This chapter explores possible effects of digitisation in three economic sectors of African economies. Based on reviews of library, security, and entertainment sectors in selected countries, we interrogate the validity of the disappearing job theory, which is reinforced by the global digital revolution. This chapter is intended to fuel the ongoing discussions about the future of jobs in Africa and the role the International Labour Organization (ILO) might play in sustaining African jobs. Since digitisation in Africa has not yet reached the same level as the developed world, its impact is mostly positive in the selected sectors. However, there is a need to manage any unintended consequences of the emerging digitised workplace. Possible interventions by the ILO and support for Africa's ability to cope with emerging changes are recommended.
\end{abstract}

\section{Introduction: Digitisation and the Changing Workplace}

Digitisation is continuing to change the workplace in major ways. In Africa, the accelerating pace of digitisation has been boosted by the increased affordability of computers and mobile telephones, and by improved skills capacities, especially among youths. Although much progress has been made in various sectors - including vehicle maintenance, aircraft and flight operations, human resource management, supplies management and procurement, education (online learning, e.g. through e-readers, online libraries, etc.), media services and finance (e.g. M-Pesa, a mobile finance app popular in Kenya and AT Ms) the applicability level, in Africa, is relatively low.

(C) STEFANO BELLUCCI AND ERIC E. OTENYO, 2019 | DOI:10.1163/9789004399013_011

This is an open access chapter distributed under the terms of the prevailing CC-BY-NC license at the time of publication. 
To further explore the concept of digitisation, let us first operationalise our key concept. According to Gartner, Inc. (2017), digitisation is the 'use of digital technologies to change a business model and provide new revenue and valueproducing opportunities; it is the process of moving to a digital business. This perspective suggests African nations will benefit from the process. Yet, as we know, African countries are far from being fully digitised. Dutta and BilbaoOsorio (2012) describe the continent as consisting of 'constrained economies', which means digitisation has yet to mature and is applicable in only limited services and industries.

Although scholars use the terms 'digitisation' and 'digitalisation' interchangeably, J. Scott Brennen and Daniel Kreiss (2016) and Beatrice Fabunmi et al. $(2009,28)$ offer conceptual clarity to emphasise that digitisation is a technical process of data conversion from analogue to digital bits. The subsequent introduction of digital technologies also leads to socio-economic changes (Hess, 2016). Digitalisation, on the other hand, refers to increased use of digital and computer technologies in organisations, countries, and workplaces in general. Casual observations would suggest that the impact of digitisation would be disruptive and lead to job losses in some sectors, and worsen unemployment in some economies.

\subsection{Youth Unemployment and Population Outlook}

The accelerated pace of digitisation in the workplace produces an increase in the productivity of labour, which results in the reduction of labour demand in a situation of weak capital investment. This conjuncture fuels the growing concerns over Africa's rising population. The African Economic Outlook reports that 'Africa's population will rise to almost 1.7 billion in 2030 and almost 2.5 billion in 2050' (AfDB et al., 2016, 41). Africa has the world's fastest growing labour force and among the highest rates of youth unemployment. For instance, in 2015 the North Africa region had the highest youth unemployment rate in the world at about 30 per cent (ILO, 2016). Africa is the most youthful continent. In all, 20 per cent of the continent's total population is comprised of people aged $15^{-24}$ and those under 30 make up around 65 per cent of the continent's over 1 billion people (AfDB, 2012, 98; ILO, 2015; UN, 2013 and 2017). Sub-Saharan Africa does not fare any better and the situation there is objectively worse when it comes to job quality. The vast majority of jobs are informal and of poor quality, with few benefits for employees (ILO, 2016; Page and Shimeles, 2014). The ILO reports that 'over 70 per cent of workers are in vulnerable employment against the global average of 46.3 per cent' (ILO, 2016). The ILO adds that employment prospects in sub-Saharan African 
countries are stagnating due to low productivity attributed to a lack of diversification in the economies (Sow, 2017).

\section{$1.2 \quad J o b$ Displacement and Its Theoretical Assumptions}

The literature on the digitisation of economies is broad and expansive. An early version of the job displacement theory was found in Jeremy Rifkin's (1996) work. Rifkin argued that unemployment would increase in most parts of the world as a result of the proliferation of information and communication technologies (ICTS) in work environments. For him, the digital revolution would adversely affect jobs in sectors such as manufacturing, retail, marketing and many service areas. According to Rifkin, by 201012 per cent of the global population would work in manufacturing and that figure would decrease to 2 per cent by 2020. Most recently, Carl Frey and Michael Osborne (2013) triggered much interest in the notion that automation and digitisation would lead to future job losses in advanced economies. They looked at jobs that were at risk as a consequence of automated technologies and estimated that over 47 per cent of jobs across all sectors were at risk of being displaced by computers. Melanie Arntz, Terry Gregory and Ulrich Zierahn (2016), Erik Brynjolfsson and Andrew McAfee (2011), and Steve Denning (2015) have discussed concerns that digitalisation might result in displacements, disruptions and jobless futures in several economies. Derek Thompson (2015) adds that job losses in certain sectors will continue to be witnessed as a result of digitisation, leading to the reduction of human labour demands with associated wage stagnation. By focusing on tasks that are easily automated and digitalised, scholars estimate that on average 9 per cent of jobs are automatable in the Organisation for Economic Co-operation and Development (OECD) countries, but they also recognise sufficient heterogeneities based on workplace organisation. However, these estimates are frequently disputed or challenged by new research insights. And in many instances there are contradictory conclusions concerning job displacement, especially because digitisation has known benefits. The opposite view is that digitisation adds jobs and value, but that the future of work will change through innovation (Eichhorst, 2014).

Building on work carried out in conjunction with Booz \& Company, Karim Sabbagh et al. (2012) consider digitisation to be ICTs' next evolution and less harmful than generally believed to many economies in the developing world. They enhance our understanding of digitisation by classifying its stages. In their formulation, most of Africa falls within the constrained economies category, which means that realisation of the full benefits of digitisation is hampered and constrained. On their scale of digitisation, African countries score 
below 25, while the best performers - the advanced countries of Europe, Australia and North America - score greater than 40 and are considered as mature in digitisation terms.

Although the studies mentioned above are generalisable, there is insufficient discussion to clarify the impacts of digitisation in labour-rich systems. For the most part, the seminal studies lack diversity in scope and range. African economies also have large informal sectors. This analysis recognises the need to develop a nuanced understanding of different sectors of the African economy in which the youth are impacted. In addition, these countries offer evidence of Tiziana Terranova's $(2013,39)$ thesis of the misappropriation of the 'fruits of cultural labor' by those who produce. We suggest theories on job displacement will be refined if data on especially informal sectors of African economies are included in the analysis. With a few exceptions, previous research has not seriously taken into consideration the impact of digitisation in African settings. For example, Bahjat El-Darwiche et al. $(2013,7)$ reported in 2011 that 600,000 jobs had been created as a result of digitisation.

Our work focuses on sectors that are sufficiently diverse to test existing theories of displacement emanating from digitisation, which are widely noted in, for instance, multinational corporation-operated banking and insurance sectors. Furthermore, David Autor (2010) has observed that displacements have occurred mainly in lower-middle-class jobs that are repetitive in nature. According to the World Bank, in African countries examples of these jobs include clerical work, the preparation of registries, bookkeeping, banking and jobs in manufacturing (The Nation, 2016; Ngunjiri, 2017; Nwachukwu, 2017; Omulo, 2017; Reuters, 2017). The sector-level approach seems to be a reasonable way by which to test the applicability of the job disappearance theory. Economists Daron Acemoglu and Pascual Restrepo (2016), among others, identify sectors, such as manufacturing, where automation eliminates job tasks more heavily than in most other job sectors. Where reductions in manufacturing have occurred, digitisation is associated with a growth in call centres, as witnessed in South Africa (Webster, 2006, 21-22).

Hopefully, the cases below provide perspectives on the cultural dynamics of digitisation, which may aid the process of finding solutions for massive unemployment on the African continent. Using documentary and other qualitative methods, we interrogate the ambiguity in claims of job displacement, focusing mainly on three instrumental sectors-libraries, security, and entertainment. Bruce Berg $(1998,216)$ observes that instrumental cases may not be viewed as typical but are helpful for refining a theoretical explanation. These cases are essential for description, which helps strengthen our explanatory abilities and implications of theoretical positions (King et al., 1994, 44). The sectors are 
examined because they offer a breeding ground for new insights, where digitisation plays a large part in tasks and jobs. In addition, the consumption of entertainment artefacts cuts across all nations and is a useful starting point from which to refine the assumptions in the disappearing job narrative.

In the remainder of this chapter we explain how digitisation has been manifest in the three sectors. We then discuss the qualitative limitations of the disappearing job theory and develop an alternative perspective on the unfolding changes in African work arenas. Finally, we discuss the implications of our perspectives for strategies by the International Labour Organization (ILO) and future outcomes.

\section{2 \\ Digitisation in Information Libraries: Cases in Kenya}

Since 2000, libraries in universities have experienced greater digitisation than the underfunded public libraries in several African cities, where these exist. The driving force for digitisation is the expected return on investment (ROI), especially tangible benefits such as lower staff time, higher productivity, faster time to delivery, reduced paper costs, reduced manually-handled information queries, increased volume or traffic, faster and more reliable inventory, reduced travel costs and a reduction in redundant records (Garson, 2006, 334-335, 419). Digital libraries and archives reduce the costs associated with the maintenance of physical spaces for storing books. At Kenyatta University, for example, the implementation of 'Digital Library Technologies' came in response to the need to provide patrons 'instant access to information sources, from any location, at any time and from any device' (Fabunmi et al., 2009; Wangila, 2014, 533-534).

In most cases, university libraries have the largest collections and most digitisation efforts have received external funding (Amollo, 2011). However, due to a weaker resource base, libraries in Kenya are at an early stage of digitisation and full assessment of the effect of digitisation on labour would be premature (Mutula, 2012, 295). Additionally, scholar Beatrice Amollo's initial assessment concluded that Kenya's digitisation process was patchy and its pace not impressive by global standards (Amollo, 2011). In Kenya, the University of Iowa's eGranary Digital Library was among the first to open its doors to African scholars, giving them access to its vast online resources. ${ }^{1}$ Further support to universities in Africa was received from partners such as Michigan State University. Because of limited government support, the digital libraries established

1 For further information, see the website https://now.uiowa.edu/2012/og/widernet-projects5ooth-library-goes-historic-kenyan-town (accessed on 6 August 2018). 
by African institutions remain relatively disorganised. Stephen Mutula (2012, 291) notes that although there had been 'staff anxiety about losing jobs, learning new skills and added responsibilities' due to the digitisation of library services in Botswana University library, transformations were successful because of policy support. In the case of the University of Nairobi, Kenya, new jobs were created in units such as ICT infrastructure management, e-Resources, the newly constituted Digital Content Unit and Multimedia Resource Centers in other universities. In addition, digital libraries expanded jobs in e-learning enterprises. As Fernando Wangila explains, digitisation at Kenyatta University 'facilitates the development and use of virtual learning environments' (Wangila, 2014, 534).

Qualitative assessment establishes that at the University of Nairobi and Kenyatta University, digitisation resulted in the retraining of employees and also created opportunities rather than displacing workers. A noted consequence of digitisation is the reskilling of library employees to facilitate navigation in the new media. No observed job displacements reported for clerical staff manually handling card catalogues were wholly attributed to digitisation.

However, should such concerns regarding potential job losses due to digitisation prove founded, then the legal framework for collective bargaining would require some rethinking. One reason for this is that matters of digitisation were not included in collective bargaining agreements (свAs) between the fragmented unions and the government, or employer. For instance, at the University of Nairobi, the Universities Academic Staff Union (UASU) represents the academic staff and senior librarians while mid-level library staff, catering and administrative staff are represented by the Kenya Universities Staff Union (KUSU). A separate union, the Kenya Union of Domestic Hotels and Educational Institutions, Hospitals, and Allied Union (KUDHEIHA) is concerned with terms and conditions of service for members of staff grades 1-5. These unions are also ill-equipped to navigate the changing nature of work in the digital age and require collaboration to advance common interests (Otenyo, 2017, 207). And these unions have to move away from silo mentalities and unions have to encourage training in the ICTs skills necessary in the knowledge economy (Otenyo, 2017, 154).

Modernisation of the security sector has much to do with the increased digitisation associated with the proliferation of closed-circuit television (CCTV) in Africa. Due to a generalised perception of deteriorating public safety and 
insecurity, CCTV has become a common feature of cities on the continent. Older analogue systems are being replaced with digital and hybrid systems. Although South Africa remains the largest market for CCTV in Africa, usage is on the rise on the continent as a whole. Most large African cities have installed IP-based CCTV in various locations. For South Africa, a combination of postapartheid insecurity and its hosting of the FIFA soccer World Cup during the summer of 2010 provided an additional motivation for heavy investments in CCTV (Minaar, 2012). What is notable is the reskilling of existing public safety employees, especially those working in Africa's large urban centres and business districts.

And there have been opportunities to create new units to oversee the CCTV management portfolio. In Kenya, for example, recruitment into the police force has increased (National Police Service Commission, 2017). Additional retailing vendor jobs have been created in the private sector as well. In Nairobi, for instance, the National Surveillance, Communication and Control System was presented as a collaboration between central government, police, and private sector vendors including Internet provider Safaricom and Huawei. Similar private-public managerial partnerships exist elsewhere such as for example in Kampala's CCTVs where Sekanyolya Systems Ltd. was the contracted private partner. It is noteworthy that the cities of Kampala and Entebbe installed CCTV to improve policing during the 2007 Commonwealth Heads of Government Meeting (CHOGM) but retained the equipment afterwards.

Similarly, the business district in Dar es Salaam had сCTV installed through contracts with the private sector. By 2014, the national parliament had urged the government to expedite the process to install CCTV in major cities (Mugarula, 2014).

Evidently, CCTV generates data and requires extremely extensive hours of viewing when crimes are being investigated. As more data is generated, new tasks are created, especially in analytics. Also, the digitalised components of the data require stable power and connectivity, which also translates into technician positions. This means more training and job creation in areas such as Big Data analytics and skills for facial recognition, among others. In addition, manpower training in analysis presents opportunities for manpower development. Because of growing needs for public safety, digitisation in the security sector does not fit into the pattern of technologies that lead to job losses or displacements. However, the evidence suggests increases in the numbers of jobs in sales and in security consultants, CCTV technicians, operators, and controllers across the continent.

Therefore, our general initial appraisal of the digitisation of CCTV is that, on balance, it has helped modernise the public safety sector and, as of now, has 
generated new types of tasks. This finding is consistent with Professor Richard Baldwin's expert observation of the security sector in advanced economies. Here, Robot Security cops, which report data in digitised forms, are an excellent example of how blending Artificial Intelligence (AI), robots and automation defines the modern workplace (Baldwin, 2017). The main challenge for African governments is to establish legal frameworks for managing the digitised security sector, such as data storage, safety, and reliability (Otenyo, 2015).

\section{4 Digitisation in the Entertainment Sector}

The economic significance of the entertainment industry cannot be minimised in the discourse on income generation and job displacement. According to The Economist (2017), music is 'Congo's [DRC] most influential export' after lucrative minerals like copper and gold. However, job displacements and disruptions have been extensively documented in the entertainment sector. Data from PricewaterhouseCoopers' (2016) research reveals the impressive job creation potential of Africa's entertainment sector. For example, Nigeria has one of the world's fastest growing entertainment sectors and its music industry will almost double in value from USD 47 million in 2015 to USD 86 million in 2020. Revenues from streaming music in Kenya are projected to rise from USD 19 million in 2016 to USD 29 million in 2020 (PricewaterhouseCoopers, 2016).

For comparative purposes, although the exact impact remains inconclusive and ambiguous, for European artists digitisation cannot be ignored in the discourses on job displacements and profitability (Bourreau et al., 2013). As Robert Klotz (2004, 171-172) explains, works in digital forms are easily copied and distributed on the Internet, which is the world's largest 'copy machine'. With the advent of 'remix culture', new forms of copyrighted works are being formed. There is also outright copycat infringement in which music and film is dubbed and shared illegally on social media platforms such as Facebook, Twitter, Soundcloud and YouTube. Two opposing views emerge: on the one hand, the emerging free culture and digitisation have, to some extent, affected the ability of creative artists to reap the full benefits of their trades and changed the game for communications businesses (Felten, 2004; Lessig, 2005; Jenkins, 2006). At the opposite end of this scale is the claim that the benefits of digitisation are recognisable and include sustainable livelihoods for artists.

In A\&M Records vs. Napster (United States Court of Appeals, 2001), evidence was provided to show that the illegal downloading of music and film is disruptive and prohibited. In addition, the Digital Millennium Copyright Act (DMCA) of 1998 tasked Internet service providers (ISPs) with reporting those infringing 
on copyrights. In Africa, attempts at formulating relevant legislation have been made. For example, the Copyright Amendment Bill (2017), ${ }^{2}$ formulated in line with the DMCA principles, is designed to punish Internet service providers for failure to expunge copyrighted content from their networks. Bloggers and websites that publish copyrighted literary content have also been sanctioned. With regard to music, in Congo musicians no longer rely on record sales but resort to other means of livelihood because of digitally enabled piracy and copyright infringements (Congo Vibes, 2014, 85; Trapido, 2016, 95; White 2008, 170-173). In Congo, piracy-related losses were exacerbated due to the government's own inability to regulate the industry. The société nationale des éditeurs, compositeurs, et auteurs (SONECA), a government entity responsible for protecting cultural products, is notoriously incompetent (White, 2008, 85). Also, for Congo, laws that prohibit copyright infringement have existed since 1982 (Ngombe, 2016). However, these laws are weak and not strictly enforced due to bureaucratic incompetence (Ngombe, 2016; WIPO, 2010).

Before the emergence of the $\mathrm{MP}_{3}$ format, in the 1970 s the unauthorised recording of music on cassette tapes had negatively impacted record sales. Brian Shimkovitz (2012) of WIRE magazine observed that the 'tape culture' was widespread in other parts of Africa. According to Shimkovitz, cassette technology became a huge movement within the music distribution industry. The popularity of tapes coincided with the explosion of piracy on the continent. Tapes also contributed to a decline in the manufacture of vinyl LPs, thereby reducing jobs at recording labels such as Decca and Philips.

Similar accounts can be offered for Tanzania, which ironically boasts of one of the oldest union bands - NUTA Jazz (the National Union of Tanzanian Trade Union Workers) (Finke, 2003, 754). Formed in 1964, NUTA, now отTU Jazz Band (Organization of Tanzanian Trade Unions), had vested interests in the welfare of musicians but lacked the capacity to protect musicians from piracy. A successor oversight body, the Tanzania Musicians Network (TMN), did not fare any better. This pattern of weak legal and bureaucratic institutions is rampant in most African countries and has attracted attention from the United Nations Educational, Scientific and Cultural Organization (UNESCO).

UNESCO, which wants artists to be meaningfully employed, plays a huge part in efforts to improve the organisational capacities of musicians. And in furtherance of its broad objectives, UNEsco developed a series of policies to

2 For further information see the Republic of South Africa (2017) Copyright Amendment Bill, http://infojustice.org/wp-content/uploads/2017/05/South-Africa-Copyright-AmendmentBill-2017.pdf (accessed on 6 August 2018). 
combat piracy in the wake of the increased use of digital technologies. ${ }^{3}$ UNESCO, through training, especially the Anti-Piracy Training for Trainers (АРTT) project and piracy awareness initiatives, has been able to make a contribution toward reducing rates of piracy. In the East Africa region, UNESCO has cooperated with law enforcement agencies and lawmakers to provide policy implementation support.

\subsection{An Alternative Perspective on the Impact of Digitisation on Entertainment Companies}

Although digitisation has been abused by unscrupulous traders, there is also an opposite view that digitisation offered benefits for entertainers and producers. The central thesis of this perspective is that 'information and communication technologies (ICTs) facilitated contacts for artists and music producers' (Brandellero and Kloosterman, 2016, 182). This perception is a dominant argument among many of the emerging musicians and artists who had been left behind in the гст-driven era of globalisation. Through exposure on social media, especially YouTube and Facebook, digitisation is said to have liberated literally millions of African artists from the narrow confines of the village and pushed them to the global stage (Shimkovitz, 2012).

The positive perspective on the role of digitisation suggests economic gains, and similar arguments can be extended to the film industry. To some degree, Nigeria's film industry is the most consequential expression of being a modern African (Bright, 2015; Haynes, 2016; Hugo, 2009). Nollywood's (Nigeria's equivalent of Hollywood in the US or Bollywood in India) rapid rise to become one of the three largest film industries in the world is evidence that the electronic age and globalisation have made an impact on Africa's entertainment sector. The industry produced at least 1,844 movies in 2015 alone (Bright, 2015). About 7,000 new titles were produced between 1992 and 2005 (Barrot, 2009). Nollywood is now a USD 3.3 billion industry making it the most lucrative of its kind in Africa (Bright, 2015).

Observers agree that Nollywood generates much revenue but that it is scattered. A great number of videos and DVDs are sold in Africa's informal streets markets. More significant is that Nigerian movies are reproduced and resold by unauthorised vendors through various digital media. This complicates the proper management of the industry. Nigeria's National Bureau of Statistics

3 Of particular importance is the establishment of the World Anti-Piracy Observatory. The various policies adopted by UNESCO in this domain can be found on the website http:// www.unesco.org/new/en/culture/themes/creativity/creative-industries/world-anti-piracyobservatory/ (accessed on 14 August 2018). 
data can only be an estimate of the industry's actual share of gross domestic product (GDP).

Many industry specialists now believe that current efforts to work with video streaming companies—-such as US-based Netflix (which is seeking to enter international markets), Africa Magic (a Naspers-owned South African Satellite TV affiliate) and Kenya's Buni.tv— to offer movie streaming services at a fee, will expand the industry. In 2012, Nigeria's iROKOtv, the country's first major online movie streaming platform, acquired exclusive rights to distribute Nollywood films. At the time of its launch, iROKOtv was referred to as the 'Netflix of Africa'. In its first year, it reported over $15^{2}$ million viewers and now has a library of over 4,80o movies, accessible from anywhere on the planet (Mulupi, 2012). A United Nation's (UN) study has declared digitisation a blessing to Kenyan movie audiences, who now pay lower rates to watch films on digital TV platforms, including Zuku and Digital Satellite Television (DStv) (UN, 2016, 27).

Thus, it is plausible that emerging digital video-on-demand (VOD) platforms are creating new job opportunities in Africa. As Kevin Zhu (2001, 273) writes, the motion picture was not previously in tune with high-tech business practices. It is only recently that advances in digital technologies changed the way we view movies. The Internet, especially broadband connection, has profoundly changed the movie distribution industry, so much so that producers and studios deliver movies directly to consumers, bypassing distribution companies. The streaming business is a fairly recent phenomenon and is poised to expand. As Dinfin Mulupi (2012) observes: 'The whole African tech scene is very exciting, dynamic, bold and ready to burst onto the global scene. Africa is just starting to come online and there is so much potential in this market, not just in Nigeria'.

Although concrete data is not available, our qualitative indicators suggest digitisation is adding jobs to the music and film industries. Consistent with Zhu (2001, 276), the impact of the digitisation of the film industry in the short-term reduces costs in the various production and distribution sectors. However, the long-term prognosis may change depending on individual sectors. Therefore, as the 'internet becomes a viable distribution channel, several types of businesses along the traditional value chain may be seriously impacted or even eliminated' (Zhu, 2001, 276). Depending on the intensity of digitisation, among the types of jobs to face reduction or elimination (or more technically, disintermediation) will be those at the previously popular video kiosks and those of hawkers common on streets of Africa's largest cities. In addition, film manufacturers, processors, and duplicators, distributors and video rental stores will be negatively affected, whether in Africa or in developed economies. The ILO 
can and should indeed play a role when it comes to supporting labour policies in this regard.

As Erik Brynjolfsson and Andrew McAfee (2011) posit, producing labour skills that cope with the fast pace of advances in technology is necessary in all economies. Perhaps the starting point is to call for additional support for Africa's weak labour governance systems and institutions and their efforts to educate workers on the global future of work concepts, especially those associated with digitisation in the workplace. Existing training institutions seem to be ill-equipped to provide the skills required for navigating through the changes brought about through digitisation as broadly defined. For example, the African Advanced Level Telecommunications Institute (AFRALTI) has an outdated curriculum (Kariuki, 2016). And even though private-public sector partnerships with corporations such as Oracle, Huawei, Microsoft and I BM exist, skills development is far behind compared to all other continents. Going forward, African countries will need more support from organisations such as the ILO. Otenyo $(2017,206)$ asserts that since unions in Africa are affiliated with the ILO, it will continue to offer development programmes for union leaders, especially with regard to navigating the interconnected world of ICTS.

Already the ILO and other units of the UN have made great efforts to support Africa's capacity to streamline its labour policies and improve the technical capacity of its workers. Additional policy changes are necessary to strengthen employment creation capacities in the near future, especially in sectors that do not receive much government support. Notwithstanding digitisation's potential to change the nature of work in the formal sector, there is room for reorganisation of informal sectors, which had previously not been able to exploit global market opportunities.

Since the 1990s, in recognition of the need for modernisation, UNESCO has supported the digitisation of library services in Kenya by offering forums and training events (Amollo, 2011). The ILO can join UNESCO and other organisations to frame jobs in the informal entertainment sector as being 'quality' or 'decent' jobs. Perhaps providing information on technological changes should be an aspect of the ILO's next agenda in the coming years. Since the two organisations have extensive collaborative experience, templates for Memorandums of Understandings (MoUs) between the ILO and UNEsco already exist and can be updated, especially in the area of addressing job security in emerging 
sectors. Areas such as film production and studio management, among others, could be provided with platforms to energise existing efforts.

Over the years, the ILO has put great efforts into the provision of decent work and social protection for vulnerable groups in Africa, which include millions in informal job sectors. For example, the ILO announced in 2012 that more than 70 per cent of workers worldwide had no statutory access to unemployment insurance, which is typical of those working in the music industry. During its 10oth Session, the International Labour Conference adopted Recommendation 22, establishing the Social Protection Floors. These are not widely debated in African parliaments but ought to be. The absence of unemployment assistance is a huge problem for African artists and many also lack business skills.

Perhaps the weak capacity within the labour movement has contributed to the failure of African governments to establish meaningful, corruption-free social protection systems. The ILO's periodic advisory warning to countries without labour rights is an important step towards building accountability structures within the African, and perhaps even global, context. The ILO continues to single out certain African countries that create conditions under which it is difficult for unions to flourish. This pressure from the ILo helps the capacity building of the key stakeholders required to put together a sustainable plan to address any future externalities arising from the digitisation of jobs, as Africa's digitisation index moves closer to the 'emerging' and 'transitional' stages of digitisation.

In Africa, the ILO could play a major role in supporting research and publications to enhance legally based policymaking processes. It can do this for the benefit of workers, especially in order to address work-related uncertainties provoked by aspects of digitisation. Although proposals to encourage workers to buy shares in companies that manufacture and develop digital products have been made in advanced countries, the landscape in Africa is different. The critical mass of workers necessary to start conversations around earning 'robot dividends' remains a mirage. The vast majority of African union leaders and policy makers will, however, need to understand the implications of digitisation and automation. Karim Sabbagh et al. (2012) emphasise that policy makers need knowledge of the benefits of digitisation. The case for this is, in fact, stronger because Africans are already major consumers of ICT products, including mobile money and social media.

Because the pace of change and level of labour displacements vary by country and industry, solutions have to be designed according to specific situations. Cooperation in areas such as ICT training can be addressed through cooperative ventures to enhance 'brain-gain' strategies. Different organisations have to 
cooperate rather than compete for human capital, especially in science, technology, engineering and math (STEM) areas, where talent is very scarce (Cann, 2016; WEF, 2017, iii). The ILO has already made policy responses to the 'brain drain' one of its action areas (ILO, 2003, 50). It may be necessary to periodically review this issue.

Various ILO reports on priorities for Africa include the creation of greater employment and income opportunities, social protection, rights at work and social dialogue. The ILO's ability to offer forums for dialogue, especially its collaboration over policies associated with the African Union and the New Partnership for Africa's Development (NEPAD), are much welcome. These initiatives recognise that any programmes for development must be Africaled. We believe these objectives have to be maintained and must especially include the restoration and maintenance of viable governance structures that will provide structures for building the capacity of states to leverage ICTs for sustainable job creation (ILO, 2003, 5). This support for governance structures should include assistance in the shape of country-level initiatives to guide union participation in protecting workers' rights to decent work and incomes.

Final Remarks

The pace of digitisation in African economies is accelerating in sectors such as security, library services and entertainment. The entertainment sector may have been a major beneficiary of the changing nature of work and leisure, thanks to digitisation. Our conclusion is that the process of embracing digitisation entails careful planning and policy management. Digital transformation is more than promoting efficiencies and upgrading software and it works best when planned and carefully executed (Andriole, 2017). This means governments should fully understand the consequences of digital transformations and be able to manage any disruptions that might occur. In the case of libraries, for example, the transformations in question need greater resource support, particularly because the economic and cultural benefits for society are enormous.

Current evidence suggests that the maturation of a digitised economy remains a work in progress. Technically, the data does not support the job displacement or disappearing theory in Africa. This is true at least for some sectors, including libraries, security and entertainment. But considering that these sectors are among the most affected by digitisation, it seems that our hypothesis is validated. The argument we are making here is that digitisation does not lead to massive job losses and could be a springboard for the creation 
of new jobs. We are aware that this chapter is a first step in understanding the effects of digitisation on job security in selected African sectors. While we have not been able to ascertain in quantitative terms the number of jobs created through digitisation efforts, the descriptive findings are generalisable in the context of the sectors selected. Still, further work is welcome.

\section{References}

Acemoglu, D. and P. Restrepo (2016) The Race Between Machine and Men: Implications of Technology for Growth, Factor Share and Employment, National Bureau of Economic Research Working Paper. No. 22252, http://www.nber.org/papers/w22252 (accessed on 3 August 2018).

AfDB (Africa Development Bank Group) (2012) African Economic Outlook, Promoting Youth Employment (Abidjan: AfDB), http://www.cpahq.org/cpahq/cpadocs/ Promoting\%20Youth\%20Employment.pdf (accessed on 3 August 2018).

AfDB, Organisation for Economic Co-operation and Development (OECD) and United Nations Development Programme (UNDP) (2016) African Economic Outlook 2016 (Abidjan: AfDB), https:/www.afdb.org/fileadmin/uploads/afdb/Documents/ Publications/AEO_2016_Report_Full_English.pdf (accessed on 6 August 2018).

Amollo, B.A. (2011) Digitization for libraries in Kenya, Paper presented at the 2nd International Conference of African Libraries and Archives (ICADLA-2), University of Witwatersrand, Johannesburg, South Africa, 14-18 November, https://core.ac.uk/ download/pdf/39670299.pdf (accessed on 6 August).

Arntz, M., T. Gregory and U. Zierahn (2016) The Risk of Automation for Jobs in OECD Countries: A Comparative Analysis, OECD Social, Employment, and Migration Papers, http://dx.doi.org/10.1787/1815199X (accessed on 6 August 2018).

Andriole, S.J. (2017) 'Five Myths About Digital Transformation', MIT Sloan Management Review, Spring Issue, http://sloanreview.mit.edu/article/five-myths-aboutdigital-transformation/ (accessed on 6 August 2018).

Autor, D. (2010) The Polarization of Job Opportunities in the U.S. Labor Market: Implications for Employment and Earnings, https://economics.mit.edu/files/5554 (accessed on 10 January 2018).

Baldwin, R. (2017) The Future of Work, Facebook Live Lecture, Graduate Institute of International and Development Studies, Geneva, http://graduateinstitute.ch/ events/_/events/corporate/2017/the-future-of-work (accessed on 15 January 2018).

Barrot, P. (ed.) (2009) The Video Phenomenon in Nigeria (Bloomington, IN: Indiana University Press).

Berg, B. (1998) Qualitative Research Methods for the Social Sciences (Boston: Allyn and Bacon). 
Bourreau, M., M. Gensollen, F. Moreau and P. Waelbroeck (2013) “'Selling less of more?” The impact of digitization on record companies', Journal of Cultural Economics, 37 (3), pp. 327-346, DOI: 10.1007/s10824-012-9184-4.

Brandellero, A. and R.C. Kloosterman (2016) 'More than just bytes? Responses to digitization in the Paris cluster of world music production', in B.J. Hracs, M. Seman and T.E. Virani (eds.) The Production and Consumption of Music in the Digital Age (New York: Routledge), pp. 177-189.

Brennen, J.S. and D. Kreiss (2016) 'Digitalization', The International Encyclopedia of Communication Theory and Philosophy (Hoboken, NJ:John Wiley \& Sons, Inc), DOI: 10.1002/9781118766804.wbiect111.

Bright, J. (2015) 'Meet "Nollywood": The second largest movie industry in the world', Fortune, 24 June, http://fortune.com/2015/06/24/nollywood-movie-industry/ (accessed on 6 August 2018).

Brynjolfsson, E. and A. McAfee (2011) Race Against the Machine: How the Digital Revolution is Accelerating Innovation, Driving Productivity, and Irreversibly Transforming Employment and the Economy (Lexington, MA: Digital Frontier Press).

Cann, O. (2016) Five million jobs by 2020: The real challenge of the Fourth Industrial Revolution. Public Engagement, 18 January, https://www.weforum.org/press/2016/o1/ five-million-jobs-by-2020-the-real-challenge-of-the-fourth-industrial-revolution/ (accessed on 6 August 2018).

Congo Vibes (2014) 'Koffi talks about piracy', Congo Vibes: Congolese Music Discussion Blog, 8 October, http://congovibes.com/congolese-music/koffi-talks-about-piracy/ (accessed on 8 August 2018).

Denning, S. (2015) 'The Jobless Future Is A Myth', Forbes Magazine, 4 June, https: //www.forbes.com/sites/stevedenning/2015/06/04/the-robots-are-not-coming/ \#70636eodig13 (accessed on 6 August 2018).

Dutta, S. and B. Bilbao-Osorio (eds.) (2012) The Global Information Technology Report, Living in a Hyperconnected World (Geneva: World Economic Forum and INSEAD), http://www3.weforum.org/docs/Global_IT_Report_2012.pdf (accessed on 13 August 2018).

Eichhorst, W. (2014) On the Future of Work in Industrialized Countries (Bonn: Institute of Labor Economics), https://www.youtube.com/watch?v=A1JOoOzAhtM (accessed on 6 August 2018).

El-Darwiche, B., F. Roman, A. Koster and M. Singh (2013) Digitization for economic growth and job creation: Regional and industry perspectives (Zurich: Strategy\& Business), https://www.strategyand.pwc.com/media/file/Digitization-for-economic-growthand-job-creation.pdf (accessed on 6 August 2018).

Fabunmi, B.A., M. Paris and M. Fabunmi (2009) 'Digitization of Library Resources: Challenges and Implications for Policy and Planning', International Journal of African and African American Studies, 5(2), pp. 23-36. 
Felten, E.W. (2004) Rip, Mix, Burn, Sue: Technology, Politics, and the Flight to Control Digital Media, Princeton University Video Clip, 12 October, https://www.cs.princeton .edu/ felten/rip/ (accessed on 6 August 2018).

Finke, J. (2003) The Rough Guide to Tanzania (London: Rough Guides).

Frey, C.B. and M. Osborne (2013) The future of employment: How susceptible are jobs to computerisation? (Oxford: Oxford University), http://www.oxfordmartin.ox.ac .uk/downloads/academic/The_Future_of_Employment.pdf (accessed on 6 August 2018).

Garson, G.D. (2006) Public Information Technology and E-Governance: Managing the Virtual State (Sudbury, MA: Jones and Bartlett).

Gartner, Inc. (2017) Digitalization, Gartner, IT Glossary, http://www.gartner.com/itglossary/digitalization (accessed on 30 January 2018).

Haynes, J. (2016) Nollywood: The Creation of Nigerian Film Genres (Chicago: Chicago University Press).

Hess, T. (2016) 'Digitalisierung', in Encyclopedia of Business Informatics Online Lexicon (Potsdam: University of Potsdam), http://www.enzyklopaedie-der -wirtschaftsinformatik.de/lexikon/technologien-methoden/Informatik --Grundlagen/digitalisierung (accessed on 14 January 2018).

Hugo, P. (2009) Nollywood (New York: Prestel Publishing).

ILO (International Labour Organization) (2016) Facing the growing unemployment challenges in Africa, Press Release, 20 January, http://www.ilo.org/addisababa/ media-centre/pr/WCMS_444474/lang--en/index.htm (accessed on 10 January 2017).

ILO (2015) Still no recovery for Africa's youth unemployment crisis, Press Release, 9 October, http://www.ilo.org/addisababa/media-centre/pr/WCMS_413566/lang--en/ index.htm (accessed on 10 January 2017).

ILO (2003) ILO activities in Africa, 2000-2003, Tenth African Regional Meeting, Addis Ababa, December 2003, Report of the Director-General (Geneva: International Labour Office), http://www.ilo.org/public/english/standards/relm/rgmeet/10afrm/dgrep.pdf (accessed on 14 January 2018).

Jenkins, H. (2006) Convergence Culture: Where Old and New Media Collide (New York: New York University Press).

Kariuki, J. (2016) 'Kenya calls for revamp of Africa ICT institute', Daily Nation, 21 September, https://www.nation.co.ke/business/Kenya-calls-for-revamp-of-Africa-ICTinsitute/996-3389656-hyoc7c/index.html (accessed on 8 August 2018).

King, G., R.O. Keohane and S. Verba (1994) Designing Social Inquiry: Scientific Inference in Qualitative Research (Princeton: Princeton University Press).

Klotz, R.J. (2004) The Politics of Internet Communications (Lanham: Rowman and Littlefield).

Lessig, L. (2005) Free Culture: The Nature and Future of Creativity (New York: Penguin Books). 
Minaar, A. (2012) 'The Growth and Further Proliferation of Camera Surveillance in South Africa', in A. Doyle, R. Lippert and D. Lyon (eds.) Eyes Everywhere: The Global Growth of Camera Surveillance (New York: Routledge), pp. 100-121.

Mugarula, F. (2014) 'TZ cities primed for spy cameras', The Citizen, 20 May, http:// www.thecitizen.co.tz/News/national/TZ-cities-primed-for-spy-cameras/18403922320594-1olicpz/index.html (accessed on 15 May 2017).

Mulupi, D. (2012) 'The Man Behind the "Netflix of Africa", Maritz Africa, 25 April, https://www.howwemadeitinafrica.com/the-man-behind-the-netflix-of-africa/ (accessed on 6 January 2018).

Mutula, S.M. (2012) 'Library Automation in Sub-Saharan Africa: Case Study of the University of Botswana', Program: Electronic Library and Information Systems, 46(3), pp. 292-307, DOI:10.1108/00330331211244832.

National Police Service Commission (2017) Statement by the Commission's Chairman Mr. Johnston Kavuludi on alleged malpractices during the recruitment of police officers, http://www.npsc.go.ke/index.php/latest-news/130-statement-by-the -commission-s-chairman-mr-johnston-kavuludi-on-alleged-malpractices-during -the-recruitment-of-police-officers (accessed on 6 September 2017).

Ngombe, Y.L. (2016) 'Copyrights, royalties, and music piracy in Congo-Brazzaville', Music in Africa, https://www.musicinafrica.net/magazine/copyrights-royalties-and -music-piracy-congo-brazzaville (accessed on 6 August 2018).

Ngunjiri, J. (2017) 'Job losses loom for Kenya workers as firms face uncertainty', Daily Nation, 29 April, https://www.businessdailyafrica.com/economy/Job-losses-loom -Kenyan-workers/3946234-3908418-lrohgw/index.html (accessed on 6 August 2018). Nwachukwu, O.J. (2017) 'Ecobank Shuts Down 74 Branches', Daily Post, 1 May, http:// dailypost.ng/2017/05/01/ecobank-shuts-74-branches/ (accessed on 6 August 2018).

Omulo, C. (2017) 'Digitisation of lands records to disrupt services', Daily Nation, 15 January, https://www.nation.co.ke/news/Digitisation-of-Lands-records-to-disrupt -services/1056-3518110-ubdewd/index.html (accessed on 6 August 2018).

Otenyo, E.E. (2017) Trade Unions and the Age of Information and Communication Technologies in Kenya (Lanham, MD: Lexington Books).

Otenyo, E.E. (2015) 'East African Cities Embrace CCTVs for Public Safety', The African Technopolitan, Volume 3, pp. 76-77, http://www.acts-net.org/images/Pubs/ Magazine/The_African_Technopolitan_July_2015_Issue.pdf (accessed on 6 August 2018).

Page, J. and A. Shimeles (2014) Aid, employment, and poverty reduction in Africa, WIDER Working Paper, 2014/o43 (Helsinki: United Nations University-WIDER), https:// www.wider.unu.edu/sites/default/files/wp2014-043.pdf (accessed on 6 August 2018).

PricewaterhouseCoopers (2016) Entertainment and Media Outlook: 2016-2020, 7 th Annual Edition, https://www.pwc.co.za/en/assets/pdf/enm/entertainment-and -media-outlook-2016-2020.pdf (accessed on 5 January 2018). 
Reuters (2017) 'Ecobank to shut down branches, cut jobs as it expands digital platforms', StandardKenya, 3 May, https://www.standardmedia.co.ke/business/article/ 2001238491/ecobank-to-shut-down-branches-cut-jobs-as-it-expands-digital-plat forms (accessed on 6 August 2018).

Rifkin, J. (1996) The End of Work: The Decline of the Global Labor Force and the Dawn of the Post-Market Era (New York: Tarcher).

Sabbagh, K., R. Friedrich, B. El-Darwiche, M. Singh, S. Ganediwalla (2012) 'Maximising the Impact of Digitization' in The Global Information Technology Report, 2012. Living in a Hyper Connected World (Geneva: WEF), http://www3.weforum.org/docs/ Global_IT_Report_2012.pdf (accessed on 29 March 2019).

Shimkovitz, B. (2012) 'Collateral damage: Awesome tapes from Africa's Brian Shimkovitz', The Wire Magazine, May, https:/www.thewire.co.uk/in-writing/essays/ collateral-damage_awesome-tapes-from-africa_s-brian-shimkovitz (accessed on 28 February 2017).

Sow, M. (2017) Figures of the week:Sub-Saharan Africa's labormarket in 2017, https://www .brookings.edu/blog/africa-in-focus/2017/o1/11/figures-of-the-week-sub-saharan -africas-labor-market-in-2017/ (accessed on 6 August 2018).

Terranova, T. (2013) 'Free Labor', in T. Scholz (ed.) Digital Labor: The Internet as Playground and Factory (New York: Routledge), pp. 33-57.

The Economist (2017) 'TheSound of Politics: Congolese Pop Music', The Economist, 14January, https://www.economist.com/news/middle-east-and-africa/21714352-oddlysymbiotic-relationship-between-some-africas-best-singers-and-worst (accessed on 6 August 2018).

The Nation (2016) 'Robots could eat all jobs in Africa', The Nation, 25 February, https:// mwnation.com/robots-could-eat-all-jobs-in-africa/ (accessed on 6 August 2018).

Thompson, D. (2015) 'A World Without Work', The Atlantic, July/August, https:// www.theatlantic.com/magazine/archive/2015/o7/world-without-work/395294/ (accessed on 5 December 2017).

Trapido, J. (2016) Breaking Rocks: Music, Ideology and Economic Collapse, from Paris to Kinshasa (New York: Berghahn Books).

UN (United Nations) (2017) World Statistics Pocketbook, Series V, No. 41 (New York, NY: United Nations), https://unstats.un.org/unsd/publications/pocketbook/files/ world-stats-pocketbook-2017.pdf (accessed on 6 August 2018).

UN (2016) The Impact of Digital Technologies and Internet on Media and Journalism in Kenya (Nairobi: UN), http://www.mediacouncil.or.ke/en/mck/jdownloads/ MEDIA\%20MONITORING\%2oREPORTS/Digital\%2omedia\%2oin\%2oKenya.pdf (accessed on 3 January 2018).

UN DESA (United Nations Department of Economic and Social Affairs) (2013) Population Division, World Population Prospects: The 2012 Revision (New York, NY: United Nations), https://esa.un.org/unpd/wpp/publications/Files/WPP2012_HIGHLIGHTS .pdf (accessed on 6 August 2018). 
United States Court of Appeals (2001) A\&M Records, Inc. v. Napster, Inc., 239 F.3d 1004. 9th Circuit. San Francisco, CA.

Wangila, F. (2014) 'An Assessment of the Implementation of Digital Library Technologies in Institutions of Higher Learning: A Case Study of Kenyatta University', International Journal of Academic Research in Business and Social Sciences, 4(9), pp. 532-541, https://ideas.repec.org/a/hur/ijarbs/v4y2014i9p532-541.html (accessed on 6 August 2018).

Webster, E. (2006) 'Trade unions and the challenge of the informalisation of work', in S. Buhlungu (ed.) Trade Unions and Democracy, COSATU workers' political attitudes in South Africa (Cape Town: HSRC Press), pp. 21-43.

White, B.W. (2008) Rumba Rules: The Politics of Dance Music in Mobutu's Zaire (Durham, NC: Duke University Press).

WEF (World Economic Forum) (2017) The Future of Jobs and Skills in Africa:Preparing the Region for the Fourth Industrial Revolution (Geneva: World Economic Forum), http://www3.weforum.org/docs/WEF_EGW_FOJ_Africa.pdf (accessed on 6 August 2018).

World Intellectual Property Organization (WIPO) (2010) The Congolese Legislative Framework in Relation to Intellectual Property, http://www.wipo.int/wipolex/en/ outline/cd.html (accessed on 6 November 2017).

Zhu, K. (2001) 'Internet-based Distribution of Digital Videos: The economic impacts of digitization on the motion picture ind ustry', Electronic Markets, 11(4), pp. 273-280, DOI: $10.1080 / 101967801753405562$. 